\title{
Management of a Complicated Internal Herniation After Roux-en-Y Gastric Bypass in a 28-Week Pregnant Woman
}

\author{
Theodoros Thomopoulos ${ }^{1}$ (i) $\cdot$ Styliani Mantziari ${ }^{1} \cdot$ Penelope St-Amour $^{1} \cdot$ Emilie Uldry $^{1} \cdot$ Michel Suter $^{1}$
}

Received: 29 July 2020 / Revised: 17 September 2020 / Accepted: 17 September 2020 / Published online: 29 September 2020

(C) The Author(s) 2020

\begin{abstract}
Background Small bowel obstruction (SBO) due to internal hernia $(\mathrm{IH})$ is a well-known late complication after laparoscopic Roux-en-Y gastric bypass (LRYGB), with an incidence between 0.5 and $10 \%$ as reported by Iannelli et al. (Obes Surg. 17(10):1283-6, 2007). It is reported most frequently $1-2$ years after surgery because of the greater weight loss at that time, with rapid loss of the mesenteric fat consequently as discussed by Stenberg et al. (Lancet. 387(10026):1397-404, 2016). Currently, women constitute more than $50 \%$ of the patients undergoing bariatric surgery and most of them are of childbearing age as reported by the World Health Organization (2015). SBO, due to IH, is a rare complication during pregnancy, mostly occurring during the third trimester as discussed by Torres-Villalobos et al. (Obes Surg 19(7):944-50, 2009), and can result in fetal and maternal morbidity and even mortality as reported by Vannevel et al. (Obstet Gynecol. 127(6):1013-20, 2016). Moreover, the physiologic changes of pregnancy can mask the symptoms of SBO after LRYGB, leading to significant diagnostic and therapeutic delays as detailed by Wax et al. (Am J Obstet Gynecol 208(4):265-71, 2013). Therefore, an early surgical exploration is necessary in this particular and uncommon situation as discussed by Webster et al. (Ann R Coll Surg Engl 97(5):339-44, 2015). Methods A 32-year-old female patient, with Ehlers-Danlos syndrome and chronic pain, was in the 28th week of her first pregnancy after bariatric surgery. She had had an antecolic LRYGB 6 years ago in another institution, resulting in a 35-kg weight loss. She presented to the emergency department with severe and persistent epigastric pain associated with nausea and vomiting during $24 \mathrm{~h}$. On physical examination, her abdomen was painful and tender at the epigastrium and left hypochondrium, and her vital signs were normal. The blood tests were in the normal range except the white blood cell count at $12^{\prime} 000 \mathrm{G} / 1$. The obstetric and neonatal team was involved, and fetal heart monitoring was normal. Abdominal ultrasonography ruled out other causes of pain. An abdominal MRI was performed and displayed a distended proximal small bowel, free abdominal fluid, and bowel mesenteric edema in the left upper quadrant with compression of the superior mesenteric vein. Internal hernia with intestinal suffering was suspected, and the patient consented for emergency laparoscopy.

Results The laparoscopic exploration, reduction of the internal hernia, and closure of the mesenteric defects are demonstrated step-by-step in the presented intraoperative video. The postoperative course was uncomplicated for both patient and fetus. Oral feeding was resumed at day 1 , with no residual symptom, and the patient was discharged on postoperative day 3. At 1-month follow-up, she had no complaint and her pregnancy had resumed a normal course. She delivered a healthy baby at 36 weeks without any complication.

Conclusions Internal herniation after LRYGB represents a rare, high-risk complication during pregnancy. A low threshold for imaging, preferably by abdominal MRI, is recommended. Multidisciplinary management, including obstetricians and bariatric
\end{abstract}

Electronic supplementary material The online version of this article (https://doi.org/10.1007/s11695-020-04997-0) contains supplementary material, which is available to authorized users.

Theodoros Thomopoulos

theodoros.thomopoulos@chuv.ch

Styliani Mantziari

styliani.mantziari@chuv.ch

Penelope St-Amour

Penelope.st-amour@chuv.ch
Emilie Uldry

emilie.uldry@chuv.ch

Michel Suter

michelsuter@netplus.ch

1 Department of Visceral Surgery, University Hospital of Lausanne (CHUV), Rue du Bugnon 46, 1011 Lausanne, Vaud, Switzerland 
surgeons, is necessary in order to avoid maternal and fetal adverse outcomes. During surgery, recognition of the anatomy is often difficult, and parts of the bowel are distended and fragile. Starting to run the bowel backwards from the ileocecal valve is a crucial surgical step for reducing internal hernias during LRYGB, and reduces both the risk to worsen the situation and of bowel injury, making its management less hazardous.

Keywords Internal herniation · Roux-en-Y gastric bypass · Laparoscopic exploration · Pregnancy

Funding Open access funding provided by University of Lausanne.

\section{Compliance with Ethical Standards}

Conflict of Interest The authors declare that they have no conflict of interest.

Ethical Approval All procedures performed in studies involving human participants were in accordance with the ethical standards of the institutional and/or national research committee and with the 1964 Helsinki Declaration and its later amendments or comparable ethical standards.

Informed Consent Informed consent was obtained from all individual participants included in the study.

Open Access This article is licensed under a Creative Commons Attribution 4.0 International License, which permits use, sharing, adaptation, distribution and reproduction in any medium or format, as long as you give appropriate credit to the original author(s) and the source, provide a link to the Creative Commons licence, and indicate if changes were made. The images or other third party material in this article are included in the article's Creative Commons licence, unless indicated otherwise in a credit line to the material. If material is not included in the article's Creative Commons licence and your intended use is not permitted by statutory regulation or exceeds the permitted use, you will need to obtain permission directly from the copyright holder. To view a copy of this licence, visit http://creativecommons.org/licenses/by/4.0/.

\section{References}

1. Iannelli A, Buratti MS, Novellas S, et al. Internal hernia as a complication of laparoscopic roux-en-Y gastric bypass. Obes Surg. 2007;17(10):1283-6.

2. Stenberg E, Szabo E, Agren G, et al. Closure of mesenteric defects in laparoscopic gastric bypass: a multicentre, randomised, parallel, open-label trial. Lancet. 2016;387(10026):1397-404.

3. World Health Organization. Obesity and overweight. Available at: http://www.who.int/mediacentre/factsheets/fs311/en/.Retrieved. October 4, 2015.

4. Torres-Villalobos GM, Kellogg TA, Leslie DB, et al. Small bowel obstruction and internal hernias during pregnancy after gastric bypass surgery. Obes Surg. 2009;19(7):944-50.

5. Vannevel V, Jans G, Bialecka M, et al. Internal herniation in pregnancy after gastric bypass: a systematic review. Obstet Gynecol. 2016;127(6):1013-20.

6. Wax JR, Pinette MG, Cartin A. Roux-en-Y gastric bypass-associated bowel obstruction complicating pregnancy-an obstetrician's map to the clinical minefield. Am J Obstet Gynecol. 2013;208(4):265-71.

7. Webster PJ, Bailey MA, Wilson J, et al. Small bowel obstruction in pregnancy is a complex surgical problem with a high risk of fetal loss. Ann R Coll Surg Engl. 2015;97(5):339-44.

Publisher's Note Springer Nature remains neutral with regard to jurisdictional claims in published maps and institutional affiliations. 